\title{
The Relationship between Nutritional Status and Latent Tuberculosis in Routine Hemodialysis
}

\author{
Ria Bandiara ${ }^{1}$ (D) Lilik Sukesi ${ }^{1}$, Astried Indrasari ${ }^{2}$, Iceu Dimas Kulsum ${ }^{3}$ (D) Mohammad Rudiansyah $^{4 *}$ (D) \\ ${ }^{1}$ Department of Internal Medicine, Division of Nephrology and Hypertension, Faculty of Medicine, Universitas Padjadjaran, \\ Hasan Sadikin Hospital, Bandung, Indonesia; ${ }^{2}$ Department of Internal Medicine, Division of Nephrology and Hypertension, \\ Faculty of Medicine, Universitas Mulawarman, Abdul Wahab Sjahranie General Hospital, Samarinda, Indonesia; ${ }^{3}$ Department \\ of Internal Medicine, Division of Respirology and Critical Respiration, Faculty of Medicine, Universitas Padjadjaran, Hasan \\ Sadikin Hospital, Bandung, Indonesia; ${ }^{4}$ Department of Internal Medicine, Division of Nephrology and Hypertension, Faculty of \\ Medicine, Universitas Lambung Mangkurat, Ulin General Hospital, Banjarmasin, Indonesia
}

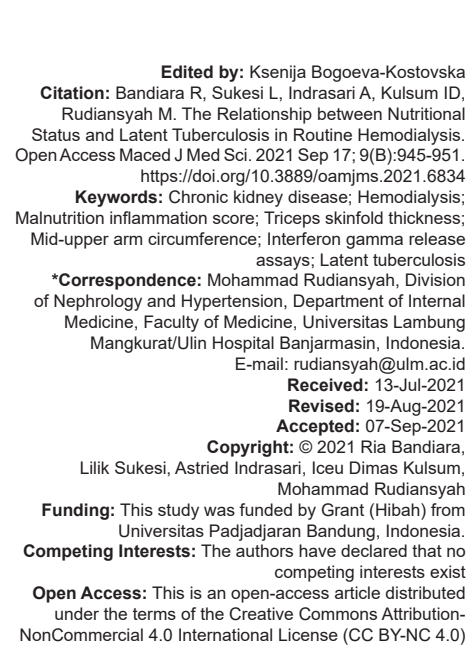

\section{Introduction}

Chronic kidney disease (CKD) remains a global health problem, affecting 5-10\% of the world's population, with increasing prevalence each year. According to the Global Burden of Disease Study in 2015, CKD is the 12 highest cause of death in the world, causing about 1.1 million deaths worldwide [1]. Meanwhile, tuberculosis (TB) is currently one of the top ten causes of death worldwide, and Indonesia has the highest prevalence of TB in the world (8\%) after India (27\%) and China (9\%) [2].

The occurrence of TB is 10-25 times higher in people with CKD and up to 37 times higher in kidney recipients [3]. This is related to uremic retention in CKD causing impaired immune response due to decreased phagocytosis function of granulocytes and monocytes/ macrophages, impaired antigen presentation capacity in antigen presenting cell (APC) cells, decreased number of antigen presentation on dendritic cell surfaces, decreased B lymphocyte production capacity, increased T lymphocyte apoptosis, and cell-mediated immunity (CMI) disorders [4].

In addition to infection in CKD patients, hemodialysis (HD) patients often suffer from protein energy wasting (PEW), and this malnutrition has a detrimental effect [5]. PEW has been shown to be an independent and strong predictor of mortality, life quality, and morbidity in people with CKD, and to be prevalent in about $18-75 \%$ of CKD-HD patients [6], [7]. Therefore, 
nutritional management is crucial for patients undergoing HD [5].

Furthermore, monitoring the protein-energy nutritional status of dialysis patients is crucial in preventing, diagnosing and treating PEW. A significant longitudinal reduction in anthropometric nutritional parameters, including weight, muscle, and fat mass, as well as an overtime rise in inflammatory markers, including C-reactive protein and pro-inflammatory cytokines, including interleukin-6, is often observed in CKD patients undergoing HD [8].

Meanwhile, a recent study conducted in Korea during 2019, on 90 CKD-HD patients, using the interferon gamma release assays (IGRA) test, reported a $22.2 \%$ prevalence of latent TB in CKD patients, and the examination of protein catabolic rate (nPCR) showed that low protein intake was associated with the risk of latent TB in the CKD population [9]. Another study on 375 CKD patients in Taiwan from 2013 to 2017 showed mid-upper arm circumference (MAC), body fat, serum creatinine, uric acid, and dialysis adequacy values were associated with a lower risk of mortality, while inflammation and hyperglycemia are associated with a greater mortality risk.

However, further studies are required to define the relationship between various nutritional markers and latent TB. Furthermore, patients with latent TB and low body mass index (BMI) are at risk of developing active TB, and malnutrition is an important risk factor for TB reactivation in dialysis patients with high risk of latent TB, partly due to the decreased CMI. Conversely, TB patients experience significant weight loss with loss of lean body mass and fat. Thus, cytokine activation and abnormal protein metabolism interact in both directions, with TB and malnutrition [9].

\section{Materials and Methods}

The participants of this study were CKD patients undergoing routine HD (CKD-HD) at the Dr. Hasan Sadikin Hospital Bandung, Indonesia, and the inclusion criteria was patients aged 18 years and above, undergoing routine HD twice weekly for over 3 months with HD frequency 2 times a week, while the exclusion criteria was patients with malignancy, human immunodeficiency virus/acquired immunodeficiency syndrome, radiological evidence or history of TB, currently receiving immunosuppressive or TB therapy.

This research is an analytical observation study, with a cross-sectional design, and the patients fulfilling the inclusion and exclusion criteria were subjected to anamnestic, physical, and supporting examinations to eliminate the possibility of active TB. Subsequently, the blood serum levels of the patients without TB symptoms were tested prior to HD, to check for IGRA. Meanwhile, personal data, including the age, gender, history of Bacille Calmette-Guerin (BCG) vaccine, CKD etiology, length of $H D, H D$ adequacy, TB contact history, number of family members, smoking status, BMI, albumin, MIS, triceps skinfold thickness (TST), biceps skinfold thickness (BST), suprailiac skinfold thickness, MAC and nPCR levels of the subjects, were also collected.

This study was conducted after approval was obtained from the health research ethics committee, Faculty of Medicine, Universitas Padjadjaran, and the Dr. Hasan Sadikin Hospital, Bandung, Indonesia. In addition, this research is part of the "TB study in CKD patients, undergoing Routine HD at the Dr. Hasan Sadikin Hospital and Habibie Kidney Special Hospital, Bandung," with research ethics number LB.02.01/X6.5/302/2019.

\section{Results}

In this study, only 120 of the 159 CKD patients undergoing routine $\mathrm{HD}$ in the HD Unit of Dr. Hasan Sadikin Hospital, Bandung, Indonesia, met the exclusion and inclusion criteria. Based on the IGRA test, 47 people $(39.17 \%)$ tested positive, 68 people $(56.67 \%)$ tested negative, while the results of the remaining $5(4.16 \%)$ were indeterminate.

Table 1 shows the basic characteristics of research subjects. The average age of the research subjects was discovered to be $47 \pm 13$ years. Meanwhile, in terms of gender distribution, there were more men (54\%) in the positive IGRA group, and more women $(58.8 \%)$, in the negative IGRA group.

Based on the urea reduction rate (URR) value, a statistically significant difference occurred between the positive and negative IGRA groups (70.45 [65.70-76.61] vs. 74.15 [70.71-77.33]), with p 0.042 (Table 2). In addition, there were more smokers and patients with history of smoking, in the positive IGRA group, compared to the negative counterpart, with a significant difference (30 [63.8\% vs. $2841.2 \% p=0.017]$ ). Furthermore, the history of previous contact with TB patients was lower in the positive IGRA group, compared to the negative counterpart; however, the values did not differ statistically.

\section{Discussion}

According to this study, the latent TB prevalence based on the IGRA test was discovered to be $39.17 \%$. This prevalence is higher compared to the report by Shu et al., at Taiwan, in 2012-2013, stating latent TB with IGRA test was $21.3 \%$, with $3.5 \%$ having indeterminate results [10]. Meanwhile, in the 
Table 1: Basic characteristics of research subjects

\begin{tabular}{|c|c|c|c|c|}
\hline Basic characteristics & Total $n=118$ & IGRA (+) $n=50$ & IGRA (-) $n=68$ & $P$ value \\
\hline \multicolumn{5}{|l|}{ Age (years) } \\
\hline Mean \pm SD & $47 \pm 13$ & $48 \pm 12$ & $47 \pm 14$ & $0.840^{\mathrm{a}}$ \\
\hline \multicolumn{5}{|l|}{ Gender } \\
\hline Male & $55(46.6)$ & $27(54.0)$ & $28(41.2)$ & \multirow[t]{2}{*}{$0.168^{\circ}$} \\
\hline Female & $63(53.4)$ & $23(46.0)$ & $40(58.8)$ & \\
\hline \multicolumn{5}{|l|}{ History of BCG Vaccine } \\
\hline Yes & $73(61.9)$ & $29(58.0)$ & $44(64.7)$ & \multirow[t]{2}{*}{$0.459^{\circ}$} \\
\hline Not & $45(38.1)$ & $21(42.0)$ & $24(35.3)$ & \\
\hline \multicolumn{5}{|l|}{ Length of HD (years) } \\
\hline Median (Range) & $50(5-177)$ & $45(6-177)$ & $53(5-147)$ & $0.442^{b}$ \\
\hline \multicolumn{5}{|l|}{ Body mass index } \\
\hline Mean \pm SD & $0.39 \pm 0.66$ & $0.32 \pm 0.56$ & $0.47 \pm 0.76$ & 0.429 \\
\hline \multicolumn{5}{|l|}{ Number of Family Members } \\
\hline 1-4 people & $78(66.1)$ & $34(68.0)$ & $44(64.7)$ & \multirow[t]{2}{*}{$0.709^{\circ}$} \\
\hline$\geq 5$ people & 40 (33.9) & $16(32.0)$ & $24(35.3)$ & \\
\hline \multicolumn{5}{|l|}{ Smoking status } \\
\hline Yes & $61(51.7)$ & $32(64.0)$ & $29(42.6)$ & \multirow[t]{2}{*}{$0.022^{\circ}$} \\
\hline Not & $57(48.3)$ & $18(36.0)$ & $39(57.4)$ & \\
\hline \multicolumn{5}{|l|}{ CKD etiology } \\
\hline Hypertension kidney disease & $62(52.5)$ & $28(56.0)$ & $34(50.0)$ & \multirow[t]{8}{*}{$0.760^{\circ}$} \\
\hline Diabetic nephropathy & $19(16.1)$ & $9(18.0)$ & $10(14.7)$ & \\
\hline Uric acid nephropathy & $4(3.4)$ & $2(4.0)$ & $2(2.9)$ & \\
\hline Lupus nephropathy & $2(1.7)$ & $1(2.0)$ & $1(1.5)$ & \\
\hline Obstructive nephropathy & $1(0.8)$ & $1(2.0)$ & $0(0.0)$ & \\
\hline Glomerulopathy & $23(19.5)$ & $7(14.0)$ & $16(23.5)$ & \\
\hline Chronic pyelonephritis & $6(5.1)$ & $2(4.0)$ & $4(5.9)$ & \\
\hline Polycystic kidney & $1(0.8)$ & $0(0.0)$ & $1(1.5)$ & \\
\hline \multicolumn{5}{|l|}{ Albumin (g/dL) } \\
\hline Median (IQR) & $3.36(3.17-3.54)$ & $3.35(3.20-3.46)$ & $3.36(3.17-3.57)$ & $0,680^{\mathrm{b}}$ \\
\hline $\mathrm{nPCR}$ & $0.72(0.24-0.95)$ & $0.69(0.38-0.98)$ & $0.70(0.24-0.98)$ & $0.649^{\mathrm{b}}$ \\
\hline
\end{tabular}

CKD: Chronic kidney disease nPCR. Normalized protein catolic rate.

multivariate analysis of the advanced-stage CKD or CKD-HD group, the independent predictors were discovered to be age, serum albumin level, need for dialysis, and history of TB [10]. A study by Chung et al., involving 167 patients in Korea, with CKD-HD, reported latent TB with $45.9 \%$ positive IGRA [11]. Three years later, Kim conducted an IGRA test on 126 kidney failure patients in the same country, about to undergo kidney transplant, and discovered positive IGRA in $42.1 \%$ of the patients [12]. Furthermore, a study by Agarwal, in India, reported positive IGRA in $36 \%$ of 185 CKD-HD patients, nearly the same rate as this research [13].

Table 2: Bivariate analysis of research variables (MIS, HD adequacy, smoking status, and TB contact history) on IGRA

\begin{tabular}{|c|c|c|c|c|}
\hline Variable & IGRA $(+) n=47$ & IGRA (-) $n=68$ & $P$ Value & OR $(95 \% \mathrm{Cl})$ \\
\hline \multicolumn{5}{|l|}{ MIS } \\
\hline$>5$ & $44(93.6)$ & $55(80.9)$ & $0.252^{\mathrm{a}}$ & $\begin{array}{l}3.467 \\
(0.929-12.932)\end{array}$ \\
\hline \multirow{2}{*}{\multicolumn{5}{|c|}{ HD adequacy }} \\
\hline & & & & \\
\hline URR & $70.45(65.70-76.61)$ & $74.15(70.71-77.33)$ & $0.042^{\mathrm{b}}$ & \\
\hline$<65$ & $11(23.4)$ & $11(16.2)$ & $0.333^{\mathrm{a}}$ & $\begin{array}{l}1.583 \\
(0.622-4.029)\end{array}$ \\
\hline $\begin{array}{l}\geq 65 \\
\text { Smoking status }\end{array}$ & $36(76.6)$ & $57(83.8)$ & & \\
\hline Smoking & $30(63.8)$ & $28(41.2)$ & $0.017^{\mathrm{b}}$ & $\begin{array}{l}2.521 \\
(1.172-5.425)\end{array}$ \\
\hline No & $17(36.2)$ & $40(58.8)$ & & \\
\hline TB contact history & $2(4.3)$ & $8(11.8)$ & $0.160^{\circ}$ & \\
\hline
\end{tabular}

In this study, the mean age of the positive and negative IGRA groups was discovered to differ insignificantly $(48 \pm 12$ vs. $47 \pm 14$ p 0.669) (Table 1 ). This is in line with the report by Rao, with a mean age of $46.4 \pm 10.4$ and $68.7 \%$ of the subjects being male [14]. However, in the study by Agarwal, with the mean age was lower, and discovered to be 36.7 \pm 12.3 years, with $69.7 \%$ of the subjects being male [13]. Meanwhile in the report by Shu, on 303 CKD-HD patients tested for IGRA, the mean age was higher, and found to be $63.5 \pm 12.7 p<0.001$ [10]

In this study, there are more total female (53\%) than male $(47 \%)$ subjects. However, the positive IGRA group had more men (55.3\%), while the negative counterpart had more women, and the two groups differed insignificantly. This is related to the existing risk factors presented by smoking habits and is in accordance with the studies by Agarwal and Rao [13], [14]. Similarly, in the general populace, there is a 2.2 times higher occurrence of TB in men, compared to women [14].

Furthermore, theduration ofHDwasshorterinthe positive IGRA group was shorter (45 [26-80]), compared to the negative counterpart (52 [28-87]); however, the difference was insignificant. This is in line the study by Shu, reporting a longer HD duration in the negative IGRA group (56.4 \pm 51.6 vs. $51.6 \pm 43.2$ months) [10]. Hemodialysis is also able to cause immune deficiency in CKD patients, through a pro-apoptotic effect due to direct blood contact with the dialysis membrane, and this often affects cell-mediated immune reactions [15].

Based on the URR values, HD adequacy was significantly lower in the positive IGRA group, compared to the negative. However, after analysis with logistic regression at URR $>65 \%$ and URR $\leq 65 \%$, this difference was discovered to be statistically insignificant, with a $p$ value of 0.333 , OR $(95 \% \mathrm{Cl}) 1.583$ (0.622-4.029), and an even higher minimum URR percentage value is possibly required. HD adequacy is closely related to toxic uremic clearance in the form of urea, during hemodialysis sessions. Furthermore, impaired immune response due to uremic retention is caused by decreased phagocytosis function of granulocytes and monocytes/macrophages, impaired antigen presentation capacity on APC cells, decreased 
number of antigen presentations on dendritic cell surfaces, decreased production capacity of B lymphocytes, increased T lymphocyte apoptosis, and CMI disorders [4].

Meanwhile, in terms of CKD etiology, most $(52.5 \%)$ patients suffered from hypertension, followed by diabetes mellitus (DM), primary glomerulopathy, chronic pyelonephritis, uric acid nephropathy, lupus nephropathy, obstructive nephropathy, and polycystic kidney disorder. The etiology of DM was also found to be more prevalent in the positive IGRA group (19.15\%) and compared to the negative (13.2\%). Furthermore, the incidence of DM has been found to increase the risk of TB, with the Ai study reporting a relative risk between 1.16 and 7.83 [16]. A report by Kumar on the DM population in India, discovered 88 patients at high risk of TB reactivation. Of these 88 patients, 44 patients had been diagnosed with DM, while the remaining 44 had no diabetes [17]. Similarly, a study by Koesoemadinata et al. on the DM population in Bandung, also reported a high prevalence of latent TB 38.9\% (95\% Cl 34.7-43.2) [18].

In addition, patients with positive IGRA were discovered to have higher MIS score, compared to the negative group (23.3 [20.0-26.7] vs. 20.0 [16.7-28.4]), without a significant difference $(p=0.252)$. This was due to subjective components, including medical history as well as physical examination, having a lower value, and objective components, body size and laboratory data, having a greater value.

The previous studies showed an optimal MIS cutoff point (MIS >5) for early malnutrition detection toward TB infection. A report by Ho on 257 stable CKD patients in Taiwan, obtained probability of death in CKD HD with MIS 3, 4, and 5 at 10.40 and $80 \%$. This shows MIS >4-5 has a significant effect on the 1 year risk of death [19]. Meanwhile, a report by Harvinder on the nutritional status examination of $155 \mathrm{HD}$ and $90 \mathrm{PD}$ patients in Malaysia, through MIS, showed MIS $\geq 5$ indications for malnutrition, and malnourishment in $88 \%$ of HD subjects, as well as $90 \%$ of PD subjects, according to the MIS scores [20].

In terms of smoking status, the positive IGRA group was discovered to have more smoking habits, and this differed statistically from the negative in the bivariate analysis, with an OR of $(95 \% \mathrm{Cl}) 2,521$ (1.172-5.425). These results are also in line with the study by Shu et al., stating smoking was the independent risk factor for latent TB is smoking, with an OR of 2.675 (1.061-6.747) [10]. Similarly, a report by Horne showed that the general population in America has an average latent TB prevalence of $5.3 \%$, while the latent TB prevalence among never smokers, current smokers, and nonsmokers was $4.1 \%, 6.6 \%$, and $6.2 \%$, respectively [21]. In the multivariable model, currently smoking was associated with latent TB (OR 1.8; 95\% Cl, 1.1-2.9).

In this study, no significant differences were recorded in the history of contact with TB patients between the positive and negative IGRA groups $(4.3 \%$ vs. $11.8 \% p=0.160)$. This is in accordance with the report by Chung on HD patients, stating no significant difference in IGRA results of high and low-risk TB patients (41.2\% vs. $44 \%$ ). Patients with high risk of latent TB are said to have a history of close contact with TB patients, old TB features on chest X-ray examination or a history of TB infection [11]. Similarly, Horne reported no significant relationship between latent $T B$ and $T B$ history, with active TB [21]. Conversely, a study by Fox in Canada, on multivariable household analysis with active TB patients obtained an OR of 14.7; 95\% Cl 1.6-137.3 [22]. The difference in this study is contact with active TB patients occurred before the occurrence of CKD and undergoing HD.

In addition, the results of albumin level examination were below normal, with a median of 3.36 (3.17-3.54) g/l. The positive IGRA group also showed a tendency to be lower, compared to the negative IGRA (3.35 [3.20-2.46] vs. 3.36 [31703.57] g/dl), with a $p$ value of 0.680 . Similarly, a report by Sayarlioglu et al., on 89 HD patients on Taiwan, obtained a positive IGRA resultof 45\% [23]. However, astudy by Baeketal. reported no significant difference in albumin levels between the two groups (3.8 [3.5-4.0] vs. 3.8 [3.4-3.9]; $p=0.429$ ), while the research by Rao et al. in India discovered low albumin (3 g/dl) was a risk factor for TB infection $(p<0.001)$ [9], [14].

Serum albumin is an acute negative reactant phase, and therefore reduces in level, during the inflammatory process. Furthermore, serum albumin is often used to measure protein reserves and possibly compromised by the occurrence of an acute infection in dialysis patients [24], [25]. Chronic infections or other infections are able reduce serum albumin concentrations because of reduced albumin synthesis within the liver, in response to increased production of the reactant acute phase [26], [27]. In the past, albumin levels have been used as a determinant of nutritional status, but this is relatively insensitive to nutritional changes. The substance is present in the body in relatively large amounts and has a half-life of 20 days, with a concentration affected by the patient's hydration state and renal function. This level usually takes 14 days to return to normal when the reserves are exhausted [28].

Meanwhile, no significant difference in $\mathrm{nPCR}$ was recorded between the positive and negative IGRA groups ( $p>0.05$ ); however, the positive group showed a tendency to has lower values. In the calculation of body size based on weight and height ratio, there was no difference in BMI between the two groups, both having $B M I \geq 20 \mathrm{~kg} / \mathrm{m}^{2}$. Similarly, Baek et al. study on 90 chronic HD patients reported no significant difference in BMI between the positive and negative IGRA groups $(23.0 \pm 3.1$ vs. $23.5 \pm 3.5 ; p=0.525)$ [9]. However, in a report by Lee et al. on $93 \mathrm{HD}$ patients, $27.3 \%$ were malnourished (BMI <20), with a positive IGRA (adjusted OR 0.46; $p=0.21$ ) [29]. 
A high BMI appeared to offer more protection to CKD-HD patients, as seen in a study by Abbot, reporting patients with BMI $>30 \mathrm{~kg} / \mathrm{m}^{2}$ with improved survival (adjusted hazard ratio (HR) 0.89 [95\% Cl: 0.81-0.99]; $p=0.042$ ) and a better 5-year survival rate of $40 \%$, compared to $32 \%$ in patients with a BMI below $30 \mathrm{~kg} / \mathrm{m}^{2}(p<0.01)$ [26]. In the HEMO study, decreased TST and MAC were associated with risk of infection-related treatment (HR 1.16 [95\% Cl: 0.98-1.37] and HR 2.45 [95\% $\mathrm{Cl}: 1.55-3.88])$ as well as all causes of death (HR 1.06 [95\% Cl: 0.99-1.13] and HR 1.58 [95\% Cl: 1.29-1.94]), especially at BMI below $25 \mathrm{~kg} / \mathrm{m}^{2}$ [26].

According to the results of analysis in Table 3, significant differences occurred in TST1, TST2, MAC1, MAC2, MAC3, and MAC Mean, between MIS >5 and MIS $\leq 5$ ( $p<0.05)$. The median of TST1, TST, MAC2, MAC3, and MAC mean was discovered to be lower at MIS $>5$, compared to MIS $\leq 5$. This is in line with a study by Yigit et al., showing a significant negative correlation between MIS scores and anthropometric examinations ([TSF, BSF, MAC, and mid-arm muscle circumference]) in hemodialysis patients [30]. Similarly, a study in China on 82 HD patients reported a significant relationship between MAC and MIS values [31].

Table 3: Anthropometric measurement based on MIS classification

\begin{tabular}{lllll}
\hline Variable & $\begin{array}{l}\text { Total } \\
\mathrm{n}=118\end{array}$ & $\begin{array}{l}\text { MIS }>5 \\
\mathrm{n}=102\end{array}$ & $\begin{array}{l}\text { MIS } \leq 5 \\
\mathrm{n}=16\end{array}$ & Nilai p \\
\hline TST 1 & $10(1-38)$ & $10(1-38)$ & $12(7-32)$ & $0.038^{*}$ \\
TST 2 & $10(1-39)$ & $10(1-39)$ & $13(7-34)$ & 0.053 \\
TST 3 & $10(1-39)$ & $10(1-39)$ & $13.5(7-34)$ & $0.038^{*}$ \\
TST Mean & $10(1-39)$ & $10(1-39)$ & $12.5(7-33)$ & 0.051 \\
BST 1 & $6(1-32)$ & $6(1-32)$ & $7(2-22)$ & 0.099 \\
BST 2 & $6(1-34)$ & $6(1-34)$ & $7.5(2-24)$ & 0.076 \\
BST 3 & $6(1-34)$ & $6(1-34)$ & $6.5(2-26)$ & 0.181 \\
BST Mean & $6(1-33)$ & $6(1-33)$ & $7(2-24)$ & 0.104 \\
SIST 1 & $12(1-42)$ & $11.5(1-42)$ & $17(2-41)$ & 0.197 \\
SIST 2 & $12(1-42)$ & $12(1-42)$ & $16.5(3-40)$ & 0.287 \\
SIST 3 & $12(1-44)$ & $12(1-44)$ & $16(3-40)$ & 0.351 \\
SIST Mean & $12(1-43)$ & $12(1-43)$ & $16.5(3-40)$ & 0.284 \\
MAC 1 & $24.0(17.0-39.4)$ & $23.8(17.0-39.4)$ & $26.9(17.1-37.8)$ & $0.042^{*}$ \\
MAC 2 & $24.2(17.0-39.5)$ & $23.8(17.0-39.5)$ & $27.0(17.0-38.0)$ & $0.037^{*}$ \\
MAC 3 & $24.2(16.8-39.6)$ & $24.0(16.8-39.6)$ & $27.2(17.0-38.2)$ & $0.033^{*}$ \\
MAC Mean & $24.1(17.0-39.5)$ & $23.85(17.0-39.5)$ & $27.05(17.0-38.0)$ & $0.038^{*}$ \\
\hline${ }^{*}$ The analysis utilized the Mann Whitney assessments. ${ }^{*}$ TST: Triceps skinfold thickness, BST: Biceps &
\end{tabular}

skinfold thickness, SIST: Suprailiac skinfold thickness, MAC: Mid-upper arm circumference.

In addition, malnutrition in TB infection decreases immune status, due to decreased lymphocyte production and immune cell proliferation ability, and this leads to increased growth of microorganisms and dissemination risk [32], [33]. The reactivation of latent TB or a previous subclinical TB infection is associated with worsened nutritional status [34].

This study is limited by the cross-sectional studies describing the situation at a time (snapshot); therefore, the causal relationship is not determined, and the representativeness is not guaranteed. Furthermore, the MIS assessment requires examination of subjective parameters, including dietary intake, gastrointestinal symptoms, functional capacity, reduced fat reserves, as well as muscle mass, and the presence of depression, fatigue, and cognitive impairment is able to the examination results.

\section{Conclusion}

The assessment of nutritional status, through TST, MAC, smoking status, and adequate HD, is crucial, because these factors present risks for latent TB in CKD patients undergoing routine HD.

\section{Acknowledgments}

This study was supported by Hasan Sadikin Hospital, Bandung, Indonesia, and the faculty of medicine, Universitas Padjadjaran Bandung, Indonesia.

\section{References}

1. World Health Organization. Latent Tuberculosis Infection: Updated and Consolidated Guidelines for Programmatic Management, Report No. 9241550236. Geneva: World Health Organization; 2018.

2. Hu H, Wu C, Huang N, Chou Y, Chang Y, Chu D. Increased risk of tuberculosis in patients with end-stage renal disease: A population-based cohort study in Taiwan, a country of high incidence of end-stage renal disease. Epidemiol Infect. 2014;142(1):191-9. https://doi.org/10.1017/ s0950268813000551

PMid:23510593

3. Zumla A, George A, Sharma V, Herbert RH, Oxley A, Oliver M. The WHO 2014 global tuberculosis report-further to go. Lancet Glob Health. 2015;3(1):e10-2. https://doi.org/10.1016/ s2214-109x(14)70361-4 PMid:25539957

4. Vaziri ND, Pahl MV, Crum A, Norris K. Effect of uremia on structure and function of immune system. J Ren Nutr. 2012;22(1):149-56. https://doi.org/10.1053/j.jrn.2011.10.020 PMid:22200433

5. Ebrahimzadehkor B, Dorri A, Yapan GA. MalnutritionInflammation Score in Hemodialysis Patients; 2014.

6. Muscaritoli M, Molfino A, Bollea MR, Fanelli FR. Malnutrition and wasting in renal disease. Curr Opin Clin Nutr Metab Care. 2009;12(4):378-83. https://doi.org/10.1097/ mco.0b013e32832c7ae1

PMid:19474712

7. Molnar MZ, Carrero JJ, Mucsi I, Remport A, Rhee CM, KalantarZadeh $\mathrm{K}$, et al. Comparison of the malnutrition-inflammation score in chronic kidney disease patients and kidney transplant recipients. Int Urol Nephrol. 2015;47(6):1025-33. https://doi. org/10.1007/s11255-015-0984-2

PMid:25931272

8. Su CT, Yabes J, Pike F, Weiner DE, Beddhu S, Burrowes JD, et al. Changes in anthropometry and mortality in maintenance hemodialysis patients in the HEMO Study. Am J Kidney Dis. 2013;62(6):1141-50. https://doi.org/10.1053/j. ajkd.2013.05.015 
PMid:23859719

9. Baek SD, Jeung S, Kang JY. Nutritional adequacy and latent tuberculosis infection in end-stage renal disease patients. Nutrients. 2019;11(10):2299. https://doi.org/10.3390/ nu11102299

PMid:31561559

10. Shu CC, Wu VC, Yang FJ, Pan SC, Lai TS, Wang JY, et al. Predictors and prevalence of latent tuberculosis infection in patients receiving long-term hemodialysis and peritoneal dialysis. PLoS One. 2012;7(8):e42592. https://doi.org/10.1371/ journal.pone.0042592

PMid:22916137

11. Chung W, Zheng Z, Sung J, Kim S, Lee H, Choi S, et al. Validity of interferon- $\gamma$-release assays for the diagnosis of latent tuberculosis in haemodialysis patients. Clin Microbiol Infect. 2010;16(7):960-5. https://doi.org/10.1111/j.1469-0691.2009.02949.x PMid:19906274

12. Kim S, Jung G, Kim S, Chang J, Kim M, Kim $Y$, et al. Comparison of the tuberculin skin test and interferon- $\gamma$ release assay for the diagnosis of latent tuberculosis infection before kidney transplantation. Infection. 2013;41(1):103-10. https://doi. org/10.1007/s15010-012-0291-0

PMid:22802098

13. Agarwal SK, Singh UB, Zaidi SH, Gupta S, Pandey RM. Comparison of interferon gamma release assay and tuberculin skin tests for diagnosis of latent tuberculosis in patients on maintenance haemodialysis. Indian J Med Res. 2015;141(4):463-8. https://doi. org/10.4103/0971-5916.159297

PMid:26112848

14. Rao TM, Ram R, Swarnalatha G, Pai BS, Ramesh V, Rao CS, et al. Tuberculosis in haemodialysis patients: A single centre experience. Indian J Nephrol. 2013;23(5):340-5. https://doi. org/10.4103/0971-4065.116296

PMid:24049269

15. Martin-Malo A, Carracedo J, Ramírez R, Rodriguez-Benot A, Soriano $\mathrm{S}$, Rodriguez $\mathrm{M}$, et al. Effect of uremia and dialysis modality on mononuclear cell apoptosis. J Am Soc Nephrol. 2000;11(5):936-42. https://doi.org/10.1681/asn.v115936 PMid:10770973

16. Ai JW, Ruan QL, Liu QH, Zhang WH. Updates on the risk factors for latent tuberculosis reactivation and their managements. Emerg Microbes Infect. 2016;5(2):e10. https://doi.org/10.1038/ emi.2016.10

PMid:26839146

17. Kumar NP, Banurekha VV, Nair D, Dolla C, Kumaran P, Babu S. Modulation of iron status biomarkers in tuberculosis-diabetes co-morbidity. Tuberculosis (Edinb). 2018;108:127-35. https:// doi.org/10.1016/j.tube.2017.11.011

PMid:29523313

18. Koesoemadinata RC, McAllister SM, Soetedjo NN, Ratnaningsih DF, Ruslami R, Kerry S, et al. Latent TB infection and pulmonary TB disease among patients with diabetes mellitus in Bandung, Indonesia. Trans R Soc Trop Med Hyg. 2017;111(2):81-9. https://doi.org/10.1093/trstmh/trx015 PMid:28419376

19. Ho LC, Wang HH, Peng YS, Chiang CK, Huang JW, Hung KY, et al. Clinical utility of malnutrition-inflammation score in maintenance hemodialysis patients: Focus on identifying the best cut-off point. Am J Nephrol. 2008;28(5):840-6. https://doi. org/10.1159/000137684

PMid: 18535370

20. Harvinder GS, Swee WC, Karupaiah T, Sahathevan S, Chinna K, Ahmad G, et al. Dialysis malnutrition and malnutrition inflammation scores: Screening tools for prediction of dialysisrelated protein-energy wasting in Malaysia. Asia Pac J Clin Nutr. 2016;25(1):26-33.

PMid:26965758

21. Horne DJ, Campo M, Ortiz JR, Oren E, Arentz M, Crothers K, et al. Association between smoking and latent tuberculosis in the US population: An analysis of the national health and nutrition examination survey. PLoS One. 2012;7(11):e49050. https://doi. org/10.1371/journal.pone. 0049050

PMid:23145066

22. Fox GJ, Lee RS, Lucas M, Khan FA, Proulx JF, Hornby K, et al. Inadequate diet is associated with acquiring Mycobacterium tuberculosis infection in an inuit community. A case-control study. Ann Am Thorac Soc. 2015;12(8):1153-62.

PMid:26099015

23. Sayarlioglu H, Gul M, Eren Dagli C DE, Sahin M, Ucar M. QuantiFERON-TB gold test for screening latent tuberculosis infection in hemodialysis patients. Tuberk Toraks. 2011;59(2):105-10. https://doi.org/10.5578/tt.2353 PMid:21740383

24. Rudiansyah M, Lubis L, Bandiara R, Supriyadi R, Afiatin, Gondodiputro RS, et al. Java barb fish gallbladder-induced acute kidney injury and ischemic acute hepatic failure. Kidney Int Rep. 2020;5(5):751-3. https://doi.org/10.1016/j. ekir.2020.03.014

PMid:32405599

25. Rudiansyah M, Bandiara R, Supriyadi R, Lubis L, Kurniaatmaja ER, Nur'amin HW, et al. The severe varicella zoster infection with kidney transplant patient using immunosuppressant. Int J Pharm Res. 2021;13(1):852-7.

26. Holmes R. Comparing Nutrition Status of in-Centre Nocturnal Hemodialysis Patients to Conventional Hemodialysis Patients: A Prospective Cohort Study: Graduate Studies; 2017.

27. Leavey SF, Strawderman RL, Young EW, Saran R, Roys E, Agodoa LY, et al. Cross-sectional and longitudinal predictors of serum albumin in hemodialysis patients. Kidney Int. 2000;58(5):2119-28. https://doi. org/10.1111/j.1523-1755.2000.00385.x

PMid: 11044233

28. Sreedhara R, Avram MM, Blanco M, Batish R, Avram MM, Mittman N. Prealbumin is the best nutritional predictor of survival in hemodialysis and peritoneal dialysis. Am J Kidney Dis. 1996;28(6):937-42. https://doi.org/10.1016/ s0272-6386(96)90398-4 PMid:8957050

29. Lee SS, Chou KJ, Dou HY, Huang TS, Ni YY, Fang HC, et al. High prevalence of latent tuberculosis infection in dialysis patients using the interferon- $\gamma$ release assay and tuberculin skin test. Clin J Am Soc Nephrol. 2010;5(8):1451-7. https://doi. org/10.2215/cjn.01790210 PMid:20538837

30. Yigit IP, Ulu R, Celiker H, Dogukan A. Evaluation of nutritional status using anthropometric measurements and MQSGA in geriatric hemodialysis patients. North Clin Istanb. 2016;3(2):124-30. https://doi.org/10.14744/nci.2016.73383 PMid:28058399

31. Chen J, Peng H, Yuan Z, Zhang K, Xiao L, Huang J, et al. Combination with anthropometric measurements and MQSGA to assess nutritional status in Chinese hemodialysis population. Int J Med Sci. 2013;10(8):974-80. https://doi.org/10.7150/ijms.5811 PMid:23801883

32. Gupta KB, Gupta R, Atreja A, Verma M, Vishvkarma S. Tuberculosis and nutrition. Lung India. 2009;26(1):9-16. https:// doi.org/10.4103/0970-2113.45198

PMid:20165588 
33. Dheda K, Schwander SK, Zhu B, van Zyl $\square$ Smit RN, Zhang Y. The immunology of tuberculosis: From bench to bedside. Respirology. 2010;15(3):433-50. https://doi. org/10.1111/j.1440-1843.2010.01739.x

PMid:20415982
34. Dai G, McMurray DN. Altered cytokine production and impaired antimycobacterial immunity in protein-malnourished guinea pigs. Infect Immun. 1998;66(8):3562-8. https://doi.org/10.1128/ iai.66.8.3562-3568.1998

PMid:9673234 